\title{
Posterior-approach single-level apical spinal osteotomy in pediatric patients for severe rigid kyphoscoliosis: long-term clinical and radiological outcomes
}

\author{
Ankit Patel, MS, Sameer Ruparel, MS, Tarun Dusad, MS, Gaurav Mehta, MS, and \\ Vishal Kundnani, MS \\ Bombay Hospital, Mumbai, India
}

\begin{abstract}
OBJECTIVE Spinal osteotomy in pediatric patients is challenging due to various factors. For correction of severe rigid kyphoscoliosis in children, numerous techniques with anterior or posterior or combined approaches, as well as multilevel osteotomies, have been described. These techniques are associated with prolonged operative times and large amounts of blood loss. The purpose of this study was to evaluate the clinical and radiologically confirmed efficacy of a modification of the apical spinal osteotomy (ASO) technique-posterior-only single-level asymmetric closing osteotomy_in pediatric patients with severe rigid kyphoscoliosis.
\end{abstract}

METHODS The authors performed a retrospective study of a case series involving pediatric patients with severe spinal deformity operated on by a single surgeon at a single institution over a period of approximately 5 years. The inclusion criteria were age $<14$ years, rigid thoracic/thoracolumbar/lumbar kyphosis $\left(>70^{\circ}\right)$ with or without neurological deficit and with or without scoliosis, and a minimum of 2 years of follow-up. Patients with cervical or lumbosacral kyphoscoliosis were excluded from the study. Demographic and clinical parameters, including age, sex, etiology of kyphoscoliosis, neurological examination status (Frankel grade), and visual analog scale (VAS) and Oswestry Disability Index (ODI) scores, were noted. Operative parameters (level of osteotomy, number of levels fused, duration of surgery, blood loss, and complications) were also recorded. Radiological assessment was done for preoperative and postoperative kyphosis and scoliosis as well as the final Cobb angle. Similarly, sagittal vertical axis (SVA) correction was calculated. Fusion was assessed in all patients at the final follow-up evaluation.

RESULTS A total of 26 pediatric patients (18 male and 8 female) with a mean age of 9 years met the inclusion criteria and had data available for analysis, and all of these patients had severe scoliosis as well as kyphosis. Comparison of preoperative and postoperative values showed a significant improvement $(p<0.05)$ in radiological, clinical, and functional parameters (Cobb angle for scoliosis and kyphosis, SVA, VAS, and ODI). With respect to kyphosis, the mean preoperative Cobb angle was $96.54^{\circ}$, the mean postoperative angle was $30.77^{\circ}$, and the mean angle at final follow-up was $34.81^{\circ}$ (average loss of correction of $4.23^{\circ}$ ), for a final average correction of $64.15 \%$. With respect to scoliosis, the mean preoperative angle was $52.54^{\circ}$, the mean postoperative angle was $15.77^{\circ}$, and the mean angle at final follow-up was $19.42^{\circ}$ (average loss of correction of $3.66^{\circ}$ ), for a final average correction of $60.95 \%$. The preoperative SVA averaged 7.6 $\mathrm{cm}$; the mean SVA improved to $3.94 \mathrm{~cm}$ at the end of 2 years. Bony fusion was achieved in all patients. The mean number of levels fused was 5.69. The mean operative time was 243.46 minutes, with an average intraoperative blood loss of $336.92 \mathrm{ml}$. Nonneurological complications occurred in $15.39 \%$ of patients ( 2 dural tears, 1 superficial infection, 1 implant failure). At the 2-year follow-up, 25 of the 26 patients had maintained or improved their neurological status. One patient developed paraplegia immediately after the operation and recovered only partially.

CONCLUSIONS Analysis of data from this series of 26 cases indicates that this posterior-approach single-level technique is effective for the correction of severe rigid kyphoscoliosis in pediatric patients, providing good clinical and radiological results in most cases.

https://thejns.org/doi/abs/10.3171/2017.12.PEDS17404

KEYWORDS kyphosis; scoliosis; deformity correction; osteotomy; posterior approach; spine

ABBREVIATIONS AP = anteroposterior; $\mathrm{ASO}=$ apical spinal osteotomy; $\mathrm{COWO}=$ closing-opening wedge osteotomy $; \mathrm{CWO}=$ closing wedge osteotomy; $\mathrm{MEP}=$ motor evoked potential; ODI = Oswestry Disability Index; PSO = pedicle subtraction osteotomy; SPO = Smith-Peterson osteotomy; SSEP = somatosensory evoked potential; SVA = sagittal vertical axis; VAS = visual analog scale; VCR = vertebral column resection.

SUBMITTED July 17, 2017. ACCEPTED December 19, 2017.

INCLUDE WHEN CITING Published online March 30, 2018; DOI: 10.3171/2017.12.PEDS17404. 
$\mathrm{T}$ HE correction of sagittal-plane deformity in pediatric patients is a challenge for the spine surgeon that has gripped the curiosity of many in the recent past. ${ }^{2,9}$ Loss of normal sagittal balance produces a posture that is at a biomechanical disadvantage and may cause spinal cord compression, giving rise to neurological symptoms. The aim of surgery is to fuse the spine in a balanced position as close to a normal configuration as possible with minimal morbidity and complications.

Correction of kyphoscoliosis can be achieved by a single posterior approach with the help of closing wedge osteotomies (CWOs), such as the Smith-Peterson osteotomy (SPO), pedicle subtraction osteotomy (PSO), and vertebral column resection (VCR). However, the anatomical limitations of a vertebral body restrict CWO to about $35^{\circ}$ lordosis. ${ }^{5,12,18}$ When sagittal imbalance exceeds $25 \mathrm{~cm}$, consideration must be given to performing more than one CWO to obtain adequate correction. ${ }^{6}$ Similarly, excessive shortening is dangerous, since the spinal cord may then be too long for the shortened column and become kinked and possibly damaged. Gertzbein and Harris ${ }^{12}$ recommended correction to $30^{\circ}-40^{\circ}$.

For the correction of severe rigid deformities through a posterior approach and osteotomy at a single level, authors have recently described modifications of conventional osteotomies like apical lordosating osteotomy, ${ }^{7}$ modified $\mathrm{VCR},{ }^{29}$ apical segmental resection osteotomy, ${ }^{10}$ and closing-opening wedge osteotomy (COWO). ${ }^{8,14}$ These surgical procedures have been associated with long operating hours and significant blood loss. ${ }^{8,14,29}$

Spinal osteotomy in pediatric patients is challenging due to various factors, including poor bone quality, rapid progression of the deformity (during physiologic growth spurts), lack of implants, and suboptimal implant purchase. The purpose of this study was to evaluate the clinical and radiological outcomes of a modification to the technique of apical spinal osteotomy (ASO), a posterior-only singlelevel osteotomy in the treatment of pediatric patients with severe rigid kyphoscoliosis, and to evaluate its clinical and radiological efficacy.

\section{Methods}

This study was designed as a retrospective analysis of cases in which patients with severe spinal deformity were treated by a single surgeon (V.K.) at our institution between November 2009 and August 2014. Additional inclusion criteria were age $<14$ years, rigid thoracic/ thoracolumbar/lumbar kyphosis $\left(>70^{\circ}\right)$ with or without neurological deficit and with or without scoliosis, and a minimum of 2 years of follow-up. Patients with cervical or lumbosacral kyphosis were excluded. Data were collected and evaluated by an independent observer. All patients underwent comprehensive clinical and radiological evaluation, and demographic, clinical, neurological examination, and radiological data were collected preoperatively and at follow-up (immediately after surgery and at 3 months, 6 months, and 1 year postoperatively, as well as at the final follow-up visit 2 years postoperatively). The patients were evaluated by the operating surgeon and a junior spine surgeon; data were collected by 2 clinical spine fellows who were not part of the operating team.

\section{Clinical Assessment}

Patient demographic data (age and sex), etiology of spinal deformity, neurological status (Frankel grade), and visual analog scale (VAS) pain scores and Oswestry Disability Index (ODI) scores were collected.

\section{Operative Assessment}

Operative parameters, including the level of osteotomy, number of levels fused, duration of surgery, intraoperative blood loss, and complications, were recorded.

\section{Radiological Assessment}

Full-length standing (with hips and knees extended) anteroposterior (AP) and lateral radiographs of the spine were available for evaluation. The level of the apical vertebra, sagittal vertical axis (SVA), and Cobb angles for kyphosis and scoliosis were documented. Fusion was assessed (using the Bridwell criteria) on follow-up radiographs by an independent observer who was not part of the surgical team. All radiological images were assessed by a clinical research fellow in our institution's radiology department with the supervision of a consultant radiologist, neither of whom was a part of the surgical team.

\section{Operative Technique}

All patients underwent 3-column spinal osteotomy, performed at the apex of their deformity-apical spinal osteotomy (ASO) - as described below.

Patients were placed prone under general anesthesia on bolsters with padding of all bony prominences. The apex of the deformity was placed over the hinge of the operating table so that when the osteotomy was closed, the table could be adjusted from a flexed position to more neutral alignment if needed. Intraoperative multimodality neuromonitoring (monitoring of somatosensory evoked potentials [SSEPs] and motor evoked potentials [MEPs] and electromyography) was used in all cases. A posterior midline incision was performed and strict subperiosteal dissection was carried out to avoid blood loss from the upper to the lower planned instrumented levels. Facets included in the fusion levels were excised to promote intraarticular arthrodesis. Pedicle screws were inserted using freehand technique and C-arm guidance. Titanium 3.5-, 4.5-, and $5.5-\mathrm{mm}$ pediatric pedicle screws were used for this purpose. Four points of fixation were secured before vertebral resection and connected with a contoured rod on one side to provide stability.

\section{Resection of the Vertebral Column}

Resection was carried out at the apex of the deformity utilizing the lever arm to the maximum effect. Because the patients in this study all had kyphosis with scoliosis, the width of the osteotomy was broader on the convex side and posteriorly for correction of both sagittal and coronal plane deformities simultaneously. The transverse process and rib heads were removed to allow complete dissection of the lateral wall of the vertebral body (Fig. 1A). Segmen- 

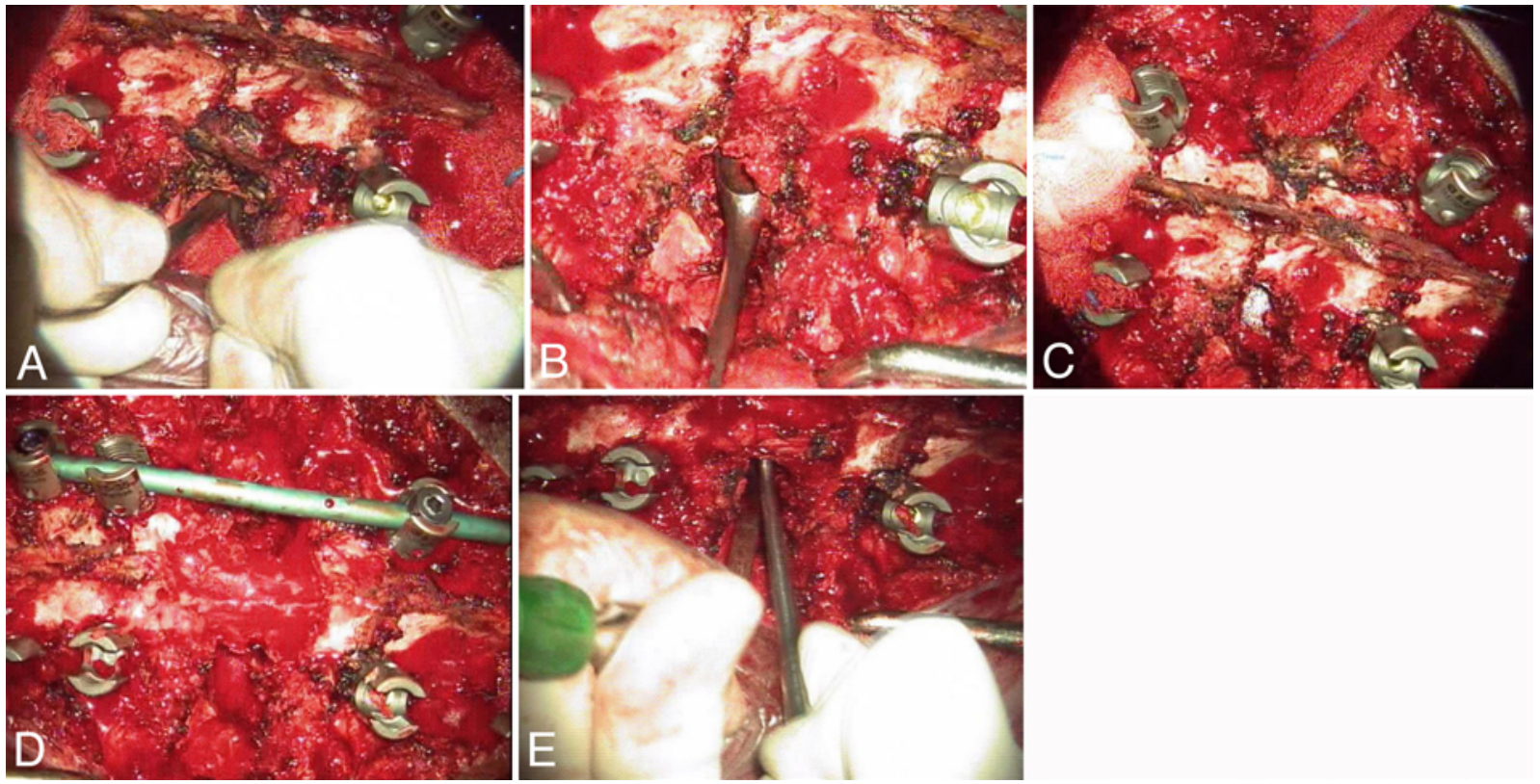

FIG. 1. Intraoperative images obtained during resection of the vertebral column. A: Meticulous subperiosteal elevation off the lateral vertebral body and anterolateral dissection with protection of pleural sac. B: Decancellation of vertebral body starting from the convex side. C: Completion of decancellation and intact spinal canal giving an avascular field (roller-gauze seen passing anterior to intact bony canal enclosing the dural sac). D: Removal of posterior elements with a Kerrison rongeur and stabilization with rod on one side. E: Breaking the posterior wall of the vertebral body with reverse angled curette. Figure is available in color online only.

tal vessels in the line of dissection were ligated and cut on only one side. Nerve roots in the thoracic region were sacrificed, if necessary, although nerve roots in the lumbar region were preserved throughout the procedure. The lateral wall of the pedicle was removed piecemeal. Vertebral body resection (Fig. 1B) was performed with the help of pituitary rongeurs, a 4-mm cutting burr, and curettes initially. Dissection was carried out until the anterior wall was removed, keeping the anterior longitudinal ligament, medial wall of the pedicle, and posterior wall of the vertebral body intact. A temporary rod was fixed on the ipsilateral side, and a similar procedure was repeated on the contralateral side. At the end of this process, a bony shell remained around the dural sac circumferentially (Fig. 1C). At this stage, the posterior vertebral wall anterior to the dural sac, the medial pedicle wall, and the laminae on the dorsal aspect of the dura were removed (Fig. 1D). This step is performed when an adequate amount of the vertebral body is resected. We believe that it helps in reducing blood loss from epidural veins and protects the dural sac from injury during the resection procedure. The posterior cortex of the vertebral body was initially thinned out with a diamond burr and was then removed (pushed down) with the help of reverse angle curettes (Fig. 1E).

\section{Deformity Correction}

Deformity correction (Fig. 2) was attempted by closure of the osteotomy with sequential rod contouring. Gradual correction of the kyphosis angle was attempted at every sequence of rod bending, with extension of the operating table if needed. In correcting scoliosis, compression and shortening was done more on the convex side and was asymmetrical. Although the mean arterial pressure was adequately maintained throughout the procedure, it is particularly important at this step to maintain spinal cord perfusion. The end point of column shortening in our series was direct visualization of dural buckling, any MEP/SSEP signal change or loss, or more than $15 \mathrm{~mm}$ of closing of the wedge on the convex side at the posterior face of the osteotomy.

\section{Arthrodesis}

Posterior fusion was performed at all instrumented levels. The number of levels to fuse was decided intraoperatively depending upon the extent of correction achieved and the gap present anteriorly after osteotomy. If the gap was less than $10 \mathrm{~mm}$ and sufficient correction was achieved with bone-on-bone contact after closure of the
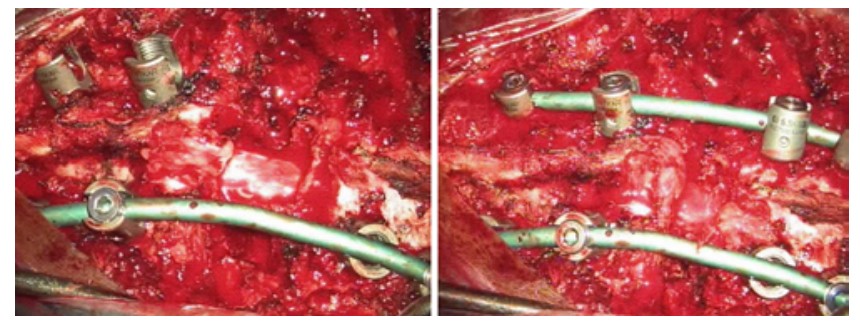

FIG. 2. Intraoperative images obtained during deformity correction. Left: Before closure of osteotomy. A precontoured rod can be seen. Right: Closure of osteotomy with compression to correct deformity in both sagittal and coronal planes. Figure is available in color online only. 
TABLE 1. Distribution of etiologies

\begin{tabular}{lc}
\hline \multicolumn{1}{c}{ Etiology } & No. of Cases \\
\hline Congenital & 8 \\
\hline Post-TB & 7 \\
\hline Neurofibromatosis & 5 \\
\hline Posttraumatic & 3 \\
\hline Idiopathic & 2 \\
\hline Scheuermann's kyphosis & 1 \\
\hline
\end{tabular}

$\mathrm{TB}=$ tuberculosis .

osteotomy, only 2 levels above and below were fused; constructs involving 3 levels above and 2 levels below or 3 levels above and below the osteotomy were also used in a few patients when needed. Considering that all patients were in the range of 6-14 years of age with a significant number of thoracic deformities, efforts were made to save as many levels as possible and thus give them a chance for better truncal height and pulmonary capacity at maturity. Anteriorly, if the residual bony defect after closing osteotomy/column shortening was less than $10 \mathrm{~mm}$, autogenous cancellous bone graft (bone chips) was placed. If the anterior gap was more than $10 \mathrm{~mm}$, a titanium mesh cage filled with bone graft was placed. The cage was precisely sized for the anterior gap and did not cause anterior column lengthening. Additional compression was applied over the cage to lock it into place and maintain optimum correction. Wound closure was performed in layers over a negative suction drain.

\section{Postoperative Treatment}

Patients were allowed to sit up in bed within 24 hours. They were allowed to mobilize out of bed on the 2 nd postoperative day with brace support. A brace was recommended for a period of 6 weeks.

\section{Statistical Analysis}

Statistical analysis was done using chi-square and Student t-tests for assessment of significance between variables; $\mathrm{p}<0.05$ was considered significant. We engaged a biostatistician for assistance with statistical analysis. A normal distribution was obtained and parametric tests were used.

\section{Results}

A total of 32 consecutive pediatric patients (21 male and 11 female) with severe kyphoscoliosis met all the criteria other than the required length of follow-up. Three of the patients were lost to follow-up and 3 had less than the required duration of follow-up; therefore, these 6 patients were excluded from analysis. Data from 26 patients (18 male and 8 female) were thus available for analysis, and these patients formed the study group. Although the inclusion criteria specified "rigid thoracic/thoracolumbar/ lumbar kyphosis $\left(>70^{\circ}\right)$... with or without scoliosis," all of the patients who met the criteria did, in fact, have both kyphosis and scoliosis.

The mean duration of follow-up for these 26 patients
TABLE 2. Neurological examination findings: Frankel's grading

\begin{tabular}{cccc}
\hline Frankel Grade & Preop & Postop & Final Follow-Up \\
\hline A & 1 & 2 & 1 \\
\hline B & 3 & 2 & 1 \\
\hline C & 5 & 1 & 0 \\
\hline D & 0 & 2 & 2 \\
\hline E & 17 & 19 & 22 \\
\hline
\end{tabular}

was 28.31 months (SD 5.14 months, range 24-48 months). The patients' mean age at the time of surgery was 9 years (SD 2.5 years, range 6-14 years).

The cause of spinal deformity varied (Table 1). Congenital kyphoscoliotic deformity was diagnosed in 8 patients, kyphoscoliosis due to post tubercular infection in 7 , neurofibromatosis in 5, posttraumatic kyphosis in 3, idiopathic kyphoscoliosis in 2, and Scheuermann's kyphosis in 1 patient.

Symptoms at presentation included mechanical back pain, cosmetic deformity of the back, and neurological symptoms. Neurological deficit was diagnosed preoperatively in 9 patients (Frankel grade $\mathrm{A}$ in 1 case, B in 3 cases, $\mathrm{C}$ in 5, and $\mathrm{E}$ in 17) (Table 2).

\section{Clinical Outcome}

At final follow-up, the Frankel grade improved from A to $B$ in 1 case, from B to D in 2 cases, and to $E$ in 1 case; in all 5 cases in which the preoperative Frankel grade was C, the grade improved to E. At the end of 2 years, all patients had maintained or improved their neurological examination status except one patient who developed paraplegia immediately after surgery and recovered only partially. One patient suffered transient left-sided L-4 weakness, which had improved to normal at the final follow-up. The final Frankel grades are shown in Table 2.

Significant improvement $(\mathrm{p}<0.05)$ also occurred in pain (VAS) and functional (ODI) scores. The mean VAS score improved from the preoperative value of 5.85 (SD 1.64 , range $2-8$ ) to 3.15 (SD 1.29 , range $2-6$ ). The mean ODI score was 56.85 (SD 19, range 20-90) preoperatively and had decreased to 19 (SD 8.24, range 10-40) at final follow-up (Table 3).

When we divided the cases into 2 subgroups based on etiology of spinal deformity (congenital or acquired), we found that the mean preoperative ODI score was 39.2 for the congenital cases and 64.7 for the acquired cases (Table 4); these mean scores improved to 24.8 and 16.4, respectively. The mean VAS score was 4.2 in the congenital cases and 6.4 in the acquired cases preoperatively and improved to 3.3 and 3.2 , respectively.

\section{Operative Outcome}

Single-level osteotomy was performed in all patients. Osteotomies were performed from levels T-5 to L-3 (Table 5 ) depending on the apex of kyphosis, most commonly at the T-12 and L-1 levels (in 13 of 26 patients). Osteotomy was done at T-10 or above in $6(23.1 \%)$ of 26 patients and at $\mathrm{T}-11$ or below in $20(76.9 \%)$ of 26 patients. The mean num- 
TABLE 3. Clinical outcomes: VAS and ODI scores

\begin{tabular}{crcc}
\hline Variable & Preop & Postop & $p$ Value \\
\hline VAS score, mean & 5.85 & 3.15 & $<0.05$ \\
\hline ODI score, mean & 56.85 & 19 & $<0.05$ \\
\hline
\end{tabular}

ber of levels fused was 5.69 (SD 0.93, range 4-8 levels). The mean operative time was 243.46 minutes (SD 48.82, range 180-390 minutes), with mean intraoperative blood loss of $336.92 \mathrm{ml}$ (SD 86.62, range 200-500 ml) (Table 6).

\section{Radiological Outcome}

The mean preoperative kyphotic Cobb angle was $96.54^{\circ}\left(\mathrm{SD} 15.73^{\circ}\right)$, with a range of $70^{\circ}-130^{\circ}$. After surgery, curves averaged $30.77^{\circ}$ (SD $10.17^{\circ}$, range $20^{\circ}-50^{\circ}$ ), yielding a significant average correction of $68.57 \%$ ( $\mathrm{p}<$ 0.05 ). At final follow-up, the mean kyphotic curve was $34.81^{\circ}$ (SD $10.15^{\circ}$, range $20^{\circ}-60^{\circ}$ ), indicating an average final correction of $64.15 \%$. An average loss of $4.23^{\circ}$ at final follow-up was documented (Table 7).

Similarly, the mean scoliotic Cobb angle improved significantly $(\mathrm{p}<0.05)$ from a preoperative value of $52.54^{\circ}$ (SD $18.13^{\circ}$, range $26^{\circ}-88^{\circ}$ ) to $15.77^{\circ}\left(\mathrm{SD} 5.07^{\circ}\right.$, range $10^{\circ}-$ $26^{\circ}$ ) postoperatively, with average correction of $68.79 \%$. At last follow-up, the mean scoliosis angle was $19.42^{\circ}$ (SD $5.31^{\circ}$, range $12^{\circ}-30^{\circ}$ ), with a mean correction of $60.95 \%$. An average loss of correction of $3.66^{\circ}$ at final follow-up was noted (Table 7).

The preoperative SVA averaged $7.6 \mathrm{~cm}$ (SD 2, range $3.5-11 \mathrm{~cm})$ and improved significantly $(\mathrm{p}<0.05)$ to 3.94 $\mathrm{cm}$ (SD 0.86, range 2.5-6 cm) at the end of 2 years. Bony fusion was achieved in all patients. Of 26 patients, 9 (34.62\%) exhibited grade 1 fusion, 15 (57.70\%) exhibited grade 2 fusion, and 1 (3.85\%) exhibited grade 3 fusion per Bridwell's criteria of radiological fusion.

\section{Complications}

Complications occurred in 8 patients $(30.77 \%)$ (Table 8). In 2 cases, dural tears were diagnosed intraoperatively and repaired primarily by suturing of the dura followed by watertight closure of the operative wound. One patient had an implant failure (screw pullout), which required revision surgery. One patient developed a superficial wound infection, which was managed conservatively with antibiotics and regular dressings. One patient (with congenital kyphoscoliosis, treated with ASO at the L-3 level) had a newonset neurological deficit involving the left L-4 nerve root (quadriceps weakness 3/5), and in 2 other patients the neurological examination findings worsened from preopera-

TABLE 4. Clinical outcomes stratified by etiology

\begin{tabular}{cccccccc}
\hline & \multicolumn{3}{c}{ ODI Score } & & \multicolumn{3}{c}{ VAS Score } \\
\cline { 2 - 4 } \cline { 6 - 8 } Etiology & Preop & Postop & $\begin{array}{c}p \\
\text { Value }\end{array}$ & Preop & Postop & $\begin{array}{c}p \\
\text { Value }\end{array}$ \\
\hline Congenital $(n=8)$ & 39.2 & 24.8 & $<0.05$ & 4.2 & 3.3 & $<0.05$ \\
\hline Acquired $(n=18)$ & 64.7 & 16.4 & $<0.05$ & 6.4 & 3.2 & $<0.05$ \\
\hline
\end{tabular}

TABLE 5. Osteotomy levels in 26 patients

\begin{tabular}{lc}
\hline Osteotomy Level & No. of Patients \\
\hline T-5 & 2 \\
\hline T-6 & 1 \\
\hline T-7 & 2 \\
\hline T-10 & 1 \\
\hline T-11 & 2 \\
\hline T-12 & 8 \\
\hline L-1 & 5 \\
\hline L-2 & 4 \\
\hline L-3 & 1 \\
\hline T-10 or above (total) & 6 \\
\hline T-11 or below (total) & 20 \\
\hline
\end{tabular}

tive Frankel grade $\mathrm{C}$ to $\mathrm{A}$ in the immediate postoperative period. One patient developed complete paraplegia (congenital kyphoscoliosis, ASO at the L-1 level), which had resolved only partially by the final follow-up evaluation. It was later realized that the osteotomy was incomplete and forced closure with load on the implants led to translation within the narrow canal. The changes in neuromonitoring signals were detected during manipulation and closure of the osteotomy. Upon realization of this, the correction maneuver was reversed with adequate ventilation, reduction of inhalational anesthetics, and maintenance of mean arterial pressure. In spite of these measures, the neuromonitoring signals did not return to baseline levels and amplitudes had increased only partially by the time closure was complete. The patient was also given a short course of intravenous steroid therapy, but only partial improvement was found in neurological status even at the final followup (Frankel grade D). The same patient suffered from screw pullout (as mentioned above) and construct failure with loss of correction, for which a revision surgery with extension of fixation and redirection of the loosened screw was performed.

\section{Illustrative Case}

This 14-year-old boy presented with a progressive back deformity and no neurological deficits. He had a positive sagittal balance with compensatory increased lumbar lordosis. Radiographs (Fig. 3) revealed block vertebrae T10-12 resulting in a rigid kyphotic deformity of $75^{\circ}$. An apical osteotomy was performed with correction of sagittal balance. The radiographs obtained 2 years postoperatively (Fig. 4) show fusion and maintained correction and sagittal balance without any implant-related complications.

\section{TABLE 6. Operative outcomes}

\begin{tabular}{crc}
\hline Variable & Mean & \multicolumn{1}{c}{ Range } \\
\hline No. of levels fused & 5.69 & \multicolumn{1}{c}{$4-8$} \\
\hline Op time (minutes) & 243.46 & $180-390$ \\
\hline Blood loss $(\mathrm{ml})$ & 336.92 & $200-500$ \\
\hline
\end{tabular}


TABLE 7. Radiological outcomes

\begin{tabular}{lcc}
\hline Timing \& Measure & Kyphosis & Scoliosis \\
\hline Preop $\left(^{\circ}\right)$ & 96.54 & 52.54 \\
\hline Postop $\left(^{\circ}\right)$ & 30.77 & 15.77 \\
\hline Final follow-up $\left(^{\circ}\right)$ & 34.81 & 19.42 \\
\hline Loss of correction $\left(^{\circ}\right)$ & 4.23 & 3.66 \\
\hline Final correction $(\%)$ & 64.15 & 60.95 \\
\hline
\end{tabular}

\section{Discussion}

The present study analyzed the clinical and radiological efficacy of apical spinal osteotomy (ASO) performed using a posterior-only single-level technique for severe rigid kyphoscoliosis in pediatric patients. The uniqueness of the study is the rarity of the study group with diverse etiologies and severity of deformity in the pediatric population. These patients were treated with a single-level osteotomy at the apex of the curve, hence the term "apical spinal osteotomy." Rigid kyphoscoliosis is quite common in young children. ${ }^{2,10,14-16,23,25,29}$ The "pitched-forward" posture causes back muscles to strain in an effort (successful or unsuccessful) to reduce the tilt, resulting in additional energy expenditure that leads to reduced functional capacity as well as a poorer quality of life due to mechanical and neurological symptoms. ${ }^{3}$ The aim of surgery is to fuse the spine in a balanced position that is as close to a normal configuration as possible.

\section{Anterior and Posterior Versus Posterior-Only Approach}

A combined anterior release and fusion followed by posterior spinal fusion and instrumentation has often been performed for large and stiff curves. ${ }^{11}$ Both open and endoscopic approaches have shown greater negative impact on pulmonary function than the posterior-only approach. ${ }^{17,19}$ Luhmann et al..$^{22}$ concluded that patients treated with pedicle screw-only instrumentation presented results similar to those for patients with combined treatment $(60.7 \%$ vs $58.5 \%$ ), without negative effects on pulmonary function from anterior release. With the advent of modern instrumentation and pedicle screw systems, a single posterior approach is preferable to reduce morbidity to the patients. All patients in the present series were operated on with a single posterior-only approach.

\section{Column-Shortening Procedures}

In highly rigid severe spinal deformities, conventional correction methods, such as posterior-only procedures or anterior release and posterior instrumentation, are usually unsatisfactory and a more aggressive approach is necessary. ${ }^{26}$ Closing wedge osteotomies, such as SPO, PSO, and VCR, can provide acceptable clinical and radiological results for patients with sagittal imbalance. ${ }^{4}$ Suk et al. reported on a posterior-only approach with a VCR for fixed lumbar spinal deformities ${ }^{26}$ as well as for severe rigid scoliosis. ${ }^{25,27}$ These authors reported excellent surgical correction with minimal long-term complications. However, anatomical limitations of vertebral bodies restrict CWO to about $35^{\circ}$ lordosis. ${ }^{5,12,18}$ When sagittal imbalance ex-
TABLE 8. Complications

\begin{tabular}{lcl}
\hline \multicolumn{1}{c}{ Complication } & No. of Patients (\%) & Final Outcome \\
\hline Dural tear & $2(7.69 \%)$ & Healed \\
\hline Implant failure & $1(3.85 \%)$ & Revision surgery \\
\hline $\begin{array}{l}\text { Superficial wound } \\
\text { infection }\end{array}$ & $1(3.85 \%)$ & Healed \\
\hline Neurological deficit & $4(15.38 \%)$ & $\begin{array}{r}\text { Recovered in 3 cases, } \\
\text { persistent in 1 case }\end{array}$ \\
\hline
\end{tabular}

ceeds $25 \mathrm{~cm}$, consideration should be given to performing more than just one CWO to obtain adequate correction, ${ }^{6}$ increasing the risks and complications of the surgery. In our technique, correction of severe rigid deformities was achieved with the help of single-level apical osteotomy for all patients. The end point of column shortening in our series was direct visualization of dural buckling, any MEP/ SSEP signal change or loss, or more than $15 \mathrm{~mm}$ of closing of the wedge on the convex side at the posterior face of the osteotomy. Also, if the residual bony defect after osteotomy closing/column shortening was less than 10 $\mathrm{mm}$, autogenous cancellous bone chips were placed. If the anterior gap was more than $10 \mathrm{~mm}$, a titanium mesh cage filled with bone graft was placed. The benefits of performing an apical osteotomy are efficient correction at the very site of rigid deformity, the potential to correct deformity in both sagittal and coronal planes, and direct bone-to-bone contact instead of spanning reconstruction, giving better fusion rates and fewer implant-related complications.

\section{Etiology and Patient Age}

Chen et al., ${ }^{10}$ Shimode et al. ${ }^{23}$ Bakaloudis et al., ${ }^{1}$ and Wang et al. ${ }^{28}$ studied rigid kyphoscoliosis of varied etiologies and have documented the efficacy of thoracic PSO, VCR, and apical resection procedures with final corrections in the range of 54\%-69\%. The mean age of the patients in these studies was in the range of 12-34 years. Similarly, Lenke et al. ${ }^{21}$ reported the results of VCR in 35 pediatric patients with a mean follow-up of 2 years. The mean age of the patients in their series was 11 years (range $2-18$ years). The patients in that case series underwent either single-level $(\mathrm{n}=20)$ or multilevel $(\mathrm{n}=15)$ osteotomies, and the authors documented overall correction rates of $51 \%-60 \%$, with an average blood loss of $691 \mathrm{ml}$. In our series, the patients' mean age was lower (9 years, range 6-14 years), all of the patients underwent single-level ASO for spinal deformities of varied etiologies as documented above, and correction rates of $64 \%$ and $60.9 \%$ were achieved for kyphotic and scoliotic curves, respectively. The mean blood loss in our series was $337 \mathrm{ml}$.

\section{Blood Loss}

Treatment of severe kyphoscoliosis with osteotomies is associated with significant blood loss. Various studies $^{7,8,14,23,29}$ on the treatment of rigid kyphoscoliosis with apical lordosating osteotomy, SWO, multilevel modified VCR, and COWO have documented blood loss in the range from 717 to $3340 \mathrm{ml}$. In their 2013 report on a multicenter trial, Lenke et al. ${ }^{20}$ emphasized the magnitude of blood 


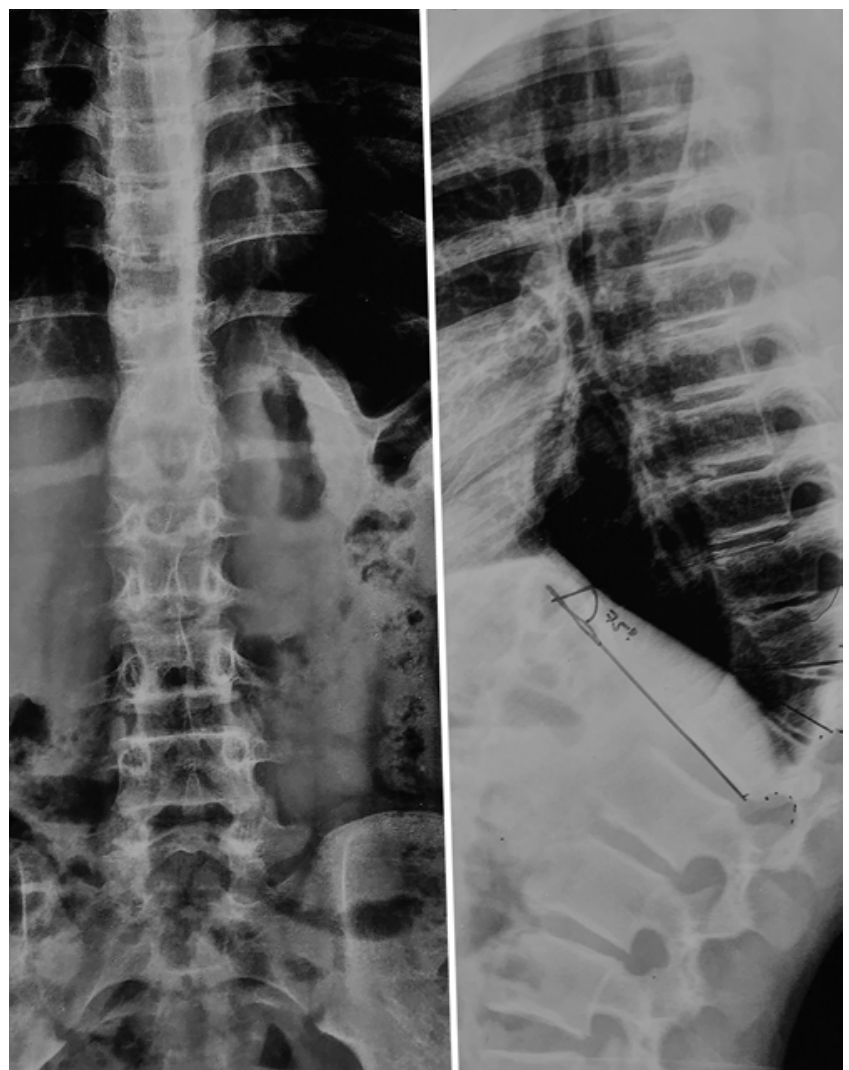

FIG. 3. Preoperative AP (left) and lateral (right) standing radiographs.

loss possible in VCR. They reported an average blood loss of $1610 \mathrm{ml}$. Similarly, Sponseller et al., ${ }^{24}$ in their study of children with neuromuscular scoliosis treated with VCR, reported a mean blood loss of $1785 \mathrm{ml}$. Our mean blood loss (337 ml, range 200-500 ml) was much less than in the previously described series. We believe that in our technique the preservation of the dural sac within the bony shell until adequate resection of the vertebral column is performed significantly prevents blood loss from the bleeding epidural veins. Also, in patients $<14$ years old the tissue planes are well delineated with minimal degeneration.

\section{Correction Magnitude}

In correction of high-magnitude rigid curves, similar correction rates have been reported for both conventional (SPO, PSO, and VCR) and newer unconventional osteotomies (apical resection osteotomy, SWO, and COWO). However, conventional osteotomies may require correction at multiple levels, which increases the morbidity of surgery. Bakaloudis et al. ${ }^{1}$ reported an overall correction of $65 \%$ with PSO in pediatric patients. Chen et al. ${ }^{10}$ documented correction of $69.87 \%$ with apical resection osteotomy. In our series, the mean kyphotic curve was $96.5^{\circ}$ preoperatively and $35^{\circ}$ at final follow-up, indicating an average final correction of $64.15 \%$, which remained essentially consistent at the end of 2 years (the change of $4.2^{\circ}$ between postoperative and final measurements was not clinically significant). Our results were similar to those

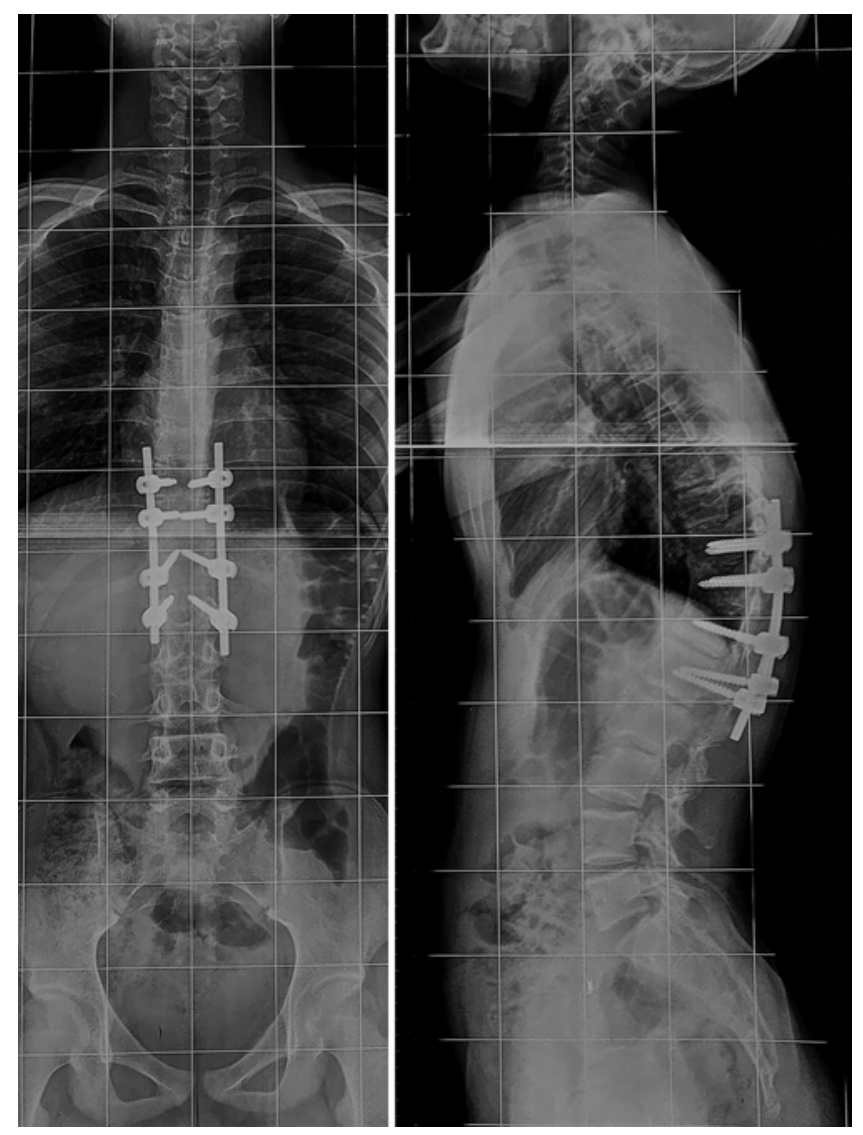

FIG. 4. Follow-up AP (left) and lateral (right) standing radiographs obtained 2 years after surgery.

of many studies mentioned in the literature, ${ }^{1,7,10,23,28}$ thus proving efficacy of the technique.

\section{Patient Satisfaction Rates}

PSO and VCR have provided good results not only in radiological terms but also in clinical terms for patients with fixed sagittal imbalance caused by multiple etiologies, but only a few studies have reported functional outcomes. After performing PSO in 27 patients with fixed sagittal imbalance, Bridwell et al. ${ }^{6}$ noted that the mean ODI score improved from 51.21 preoperatively to 35.75 at the last follow-up evaluation, and $92.3 \%$ of the patients were found to be satisfied with the treatment according to the overall satisfaction score. Kalra et al. ${ }^{13}$ also described the ODI score as having decreased from the preoperative 56.26 to 11.2 after surgery in 15 patients with rigid tuberculous kyphosis. In a similar study involving 35 patients with fixed sagittal balance, Kim et al. ${ }^{16}$ reported the improvement of the mean ODI score from 49 to 24 and very good satisfaction in $87 \%$ of the patients. Corresponding to the aforementioned results, our study did demonstrate a significant decrease in the mean ODI score after surgery (from 57 to 19) and good functional improvement at the final follow-up evaluation. In addition, when ODI and VAS scores in our study were divided into 2 subgroups based on the etiology of spinal deformity (congenital or acquired), the mean preoperative ODI score was 39.2 in the congeni- 
tal cases and 64.7 in the acquired cases, which improved to 24.8 and 16.4 , respectively, and the mean preoperative VAS score was 4.2 in the congenital cases and 6.4 in the acquired cases, which improved to 3.3 and 3.2, respectively. This interesting paradoxical finding of greater improvement in the ODI and VAS scores because of higher pain and disability scores preoperatively in the acquired cases may have occurred because in the congenital group most patients presented with deformity, whereas in the acquired group pain was a common presenting feature.

\section{Complications}

Bakaloudis et al. ${ }^{1}$ reported 5 medical complications and 1 neurological complication in their series of 12 patients, for a complication rate of 50\%. Similarly, Chang et al. ${ }^{8}$ reported complications in 41 of 83 patients in their series, documenting a complication rate of around $50 \%$. Kawahara et al. ${ }^{14}$ reported no neurological complications. However, their study was small, including only 7 patients. Chen et al.$^{10}$ documented complications in 10 of 23 patients. Lenke et al. ${ }^{21}$ reported complications in only 4 of 35 patients in their series of pediatric deformity patients operated on with VCR. However, an alarming rate of complications associated with VCR in pediatric patients was noted in a multicenter trial that included 147 patients. ${ }^{20}$ The authors observed complications in 59\% of these patients. Sixtyeight patients had a complication during surgery (the most common being changes in spinal cord monitoring data and blood loss $>2 \mathrm{~L}$ ), and 43 had a postoperative complication (most often respiratory related). No patient in their series had a complete permanent neurological deficit.

In our series, the overall complication rate was $30.77 \%$. There was a general complication rate of $15 \%$, which included 2 cases of dural tear and 1 case each of implant failure and superficial infection. The neurological complication rate was $7.6 \%$. One patient had a new-onset neurological deficit involving the left L-4 nerve root (quadriceps weakness 3/5), and in 2 other patients the neurological examination results worsened from preoperative Frankel grade $\mathrm{C}$ to $\mathrm{A}$ in the immediate postoperative period. In these 3 cases, the patients' deficits all had improved with conservative management at the 3-month follow-up. One patient, however, developed complete paraplegia (congenital kyphoscoliosis, ASO at the L-1 level) that resolved only partially by the final follow-up evaluation. This complication was later found to be attributable to incomplete osteotomy and forced closure with load on the implants, which led to translation within the narrow canal. Neuromonitoring signal changes were detected during manipulation and closure of the osteotomy and reversal measures were taken (as described in detail in Results), but only partial improvement was found in neurological status even at the final follow-up (Frankel grade D). The same patient suffered from screw pullout and construct failure with loss of correction, for which a revision surgery with extension of fixation and redirection of the loosened screw was performed. The learning points from this case were that osteotomy should be completed before closure is attempted to avoid translation over a hinge. In addition, forced closure leads to excessive stress on implants, which can lead to implant failure and pseudarthrosis. Intraoperative neuro- monitoring is an essential tool for a deformity surgeon, as multimodal monitoring acts to warn when damage is done and aids in timely performance of corrective measures. In our case, timely reversal led to partial recovery, which would otherwise have been a complete and irreversible neurological deficit. All other patients in the series had improved with conservative management at the 3-month follow-up.

\section{Limitations}

The major limitation of this study is its retrospective design; however, the database for this study was constructed without any hypothesis, and the data were thus collected free from any bias related to the study. Nevertheless, we recognize that prospective data collection would have strengthened the salient points. Another limitation of the study is the small number of cases with varied etiology and a relatively short follow-up. A longer duration of follow-up and larger groups of cases with similar etiology could help elucidate the effect of etiology on correction and morbidity with the technique. Longer follow-up would allow for more observation of the pitfalls of long-segment fusion in the pediatric population, and the effect of residual deformity resulting in mechanical back pain, implant loosening, and loss of correction can be evaluated better. Another limitation of the study was the use of the ODI as an outcome measure, although it has not been validated in the pediatric age group. The ODI was used because there were no validated pediatric outcome measures available in the local language at the time of data collection. Moreover, all of the questions were answered by parents, so a bias of subjective effect on evaluation cannot be ruled out.

\section{Conclusions}

In this paper, we described our technique of singlelevel apical spinal osteotomy (ASO) through a posterior approach for the treatment of severe rigid pediatric kyphoscoliosis. The technique can be performed in small children with good clinical and radiological results and satisfactory correction rates. Although the procedure is technically demanding, it can be reliably executed by any skilled spine surgeon familiar with decompression surgery and instrumentation techniques. It is versatile and effective for correction of rigid kyphoscoliosis in children, the treatment of which to date has proved to be extremely difficult, even in experienced hands.

\section{References}

1. Bakaloudis G, Lolli F, Di Silvestre M, Greggi T, Astolfi S, Martikos K, et al: Thoracic pedicle subtraction osteotomy in the treatment of severe pediatric deformities. Eur Spine J 20 (Suppl 1):S95-S104, 2011

2. Berven SH, Deviren V, Smith JA, Emami A, Hu SS, Bradford DS: Management of fixed sagittal plane deformity: results of the transpedicular wedge resection osteotomy. Spine (Phila Pa 1976) 26:2036-2043, 2001

3. Booth KC, Bridwell KH, Lenke LG, Baldus CR, Blanke KM: Complications and predictive factors for the successful treatment of flatback deformity (fixed sagittal imbalance). Spine (Phila Pa 1976) 24:1712-1720, 1999

4. Bradford DS, Tay BK, Hu SS: Adult scoliosis: surgical indi- 
cations, operative management, complications, and outcomes Spine (Phila Pa 1976) 24:2617-2629, 1999

5. Bridwell KH: Decision making regarding Smith-Petersen vs. pedicle subtraction osteotomy vs. vertebral column resection for spinal deformity. Spine (Phila Pa 1976) 31 (19 Suppl):S171-S178, 2006

6. Bridwell KH, Lewis SJ, Lenke LG, Baldus C, Blanke K: Pedicle subtraction osteotomy for the treatment of fixed sagittal imbalance. J Bone Joint Surg Am 85-A:454-463, 2003

7. Chang KW, Chen YY, Lin CC, Hsu HL, Pai KC: Apical lordosating osteotomy and minimal segment fixation for the treatment of thoracic or thoracolumbar osteoporotic kyphosis. Spine (Phila Pa 1976) 30:1674-1681, 2005

8. Chang KW, Cheng CW, Chen HC, Chang KI, Chen TC: Closing-opening wedge osteotomy for the treatment of sagittal imbalance. Spine (Phila Pa 1976) 33:1470-1477, 2008

9. Cheh G, Lenke LG, Padberg AM, Kim YJ, Daubs MD, Kuhns C, et al: Loss of spinal cord monitoring signals in children during thoracic kyphosis correction with spinal osteotomy: why does it occur and what should you do? Spine (Phila Pa 1976) 33:1093-1099, 2008

10. Chen Z, Zeng Y, Li W, Guo Z, Qi Q, Sun C: Apical segmental resection osteotomy with dual axial rotation corrective technique for severe focal kyphosis of the thoracolumbar spine. J Neurosurg Spine 14:106-113, 2011

11. Dubousset J, Herring JA, Shufflebarger H: The crankshaft phenomenon. J Pediatr Orthop 9:541-550, 1989

12. Gertzbein SD, Harris MB: Wedge osteotomy for the correction of posttraumatic. kyphosis. Spine (Phila Pa 1976) 17:374-379, 1992

13. Kalra KP, Dhar SB, Shetty G, Dhariwal Q: Pedicle subtraction osteotomy for rigid post-tuberculous kyphosis. J Bone Joint Surg Br 88:925-927, 2006

14. Kawahara N, Tomita K, Baba H, Kobayashi T, Fujita T, Murakami H: Closing-opening wedge osteotomy to correct angular kyphotic deformity by a single posterior approach. Spine (Phila Pa 1976) 26:391-402, 2001

15. Kim KT, Lee SH, Suk KS, Lee JH, Jeong BO: Outcome of pedicle subtraction osteotomies for fixed sagittal imbalance of multiple etiologies: a retrospective review of 140 patients. Spine (Phila Pa 1976) 37:1667-1675, 2012

16. Kim YJ, Bridwell KH, Lenke LG, Cheh G, Baldus C: Results of lumbar pedicle subtraction osteotomies for fixed sagittal imbalance: a minimum 5-year follow-up study. Spine (Phila Pa 1976) 32:2189-2197, 2007

17. Kim YJ, Lenke LG, Bridwell KH, Kim KL, Steger-May K: Pulmonary function in adolescent idiopathic scoliosis relative to the surgical procedure. J Bone Joint Surg Am 87:15341541,2005

18. Lehmer SM, Keppler L, Biscup RS, Enker P, Miller SD, Steffee AD: Posterior transvertebral osteotomy for adult thoracolumbar kyphosis. Spine (Phila Pa 1976) 19:2060-2067, 1994

19. Lenke LG, Newton PO, Marks MC, Blanke KM, Sides B, Kim YJ, et al: Prospective pulmonary function comparison of open versus endoscopic anterior fusion combined with posterior fusion in adolescent idiopathic scoliosis. Spine (Phila Pa 1976) 29:2055-2060, 2004

20. Lenke LG, Newton PO, Sucato DJ, Shufflebarger HL, Emans JB, Sponseller PD, et al: Complications after 147 consecutive vertebral column resections for severe pediatric spinal deformity: a multicenter analysis. Spine (Phila Pa 1976) 38:119-132, 2013

21. Lenke LG, O’Leary PT, Bridwell KH, Sides BA, Koester LA, Blanke KM: Posterior vertebral column resection for severe pediatric deformity: minimum two-year follow-up of thirtyfive consecutive patients. Spine (Phila Pa 1976) 34:22132221, 2009

22. Luhmann SJ, Lenke LG, Kim YJ, Bridwell KH, Schootman M: Thoracic adolescent idiopathic scoliosis curves between 70 degrees and 100 degrees: is anterior release necessary? Spine (Phila Pa 1976) 30:2061-2067, 2005

23. Shimode M, Kojima T, Sowa K: Spinal wedge osteotomy by a single posterior approach for correction of severe and rigid kyphosis or kyphoscoliosis. Spine (Phila Pa 1976) 27:2260 2267, 2002

24. Sponseller PD, Jain A, Lenke LG, Shah SA, Sucato DJ, Emans JB, et al: Vertebral column resection in children with neuromuscular spine deformity. Spine (Phila Pa 1976) 37:E655-E661, 2012

25. Suk SI, Chung ER, Kim JH, Kim SS, Lee JS, Choi WK: Posterior vertebral column resection for severe rigid scoliosis. Spine (Phila Pa 1976) 30:1682-1687, 2005

26. Suk SI, Chung ER, Lee SM, Lee JH, Kim SS, Kim JH: Posterior vertebral column resection in fixed lumbosacral deformity. Spine (Phila Pa 1976) 30:E703-E710, 2005

27. Suk SI, Kim JH, Kim WJ, Lee SM, Chung ER, Nah KH: Posterior vertebral column resection for severe spinal deformities. Spine (Phila Pa 1976) 27:2374-2382, 2002

28. Wang Y, Lenke LG: Vertebral column decancellation for the management of sharp angular spinal deformity. Eur Spine J 20:1703-1710, 2011

29. Wang Y, Zhang Y, Zhang X, Huang P, Xiao S, Wang Z, et al: A single posterior approach for multilevel modified vertebral column resection in adults with severe rigid congenital kyphoscoliosis: a retrospective study of 13 cases. Eur Spine J 17:361-372, 2008

\section{Disclosures}

The authors report no conflict of interest concerning the materials or methods used in this study or the findings specified in this paper.

\section{Author Contributions}

Conception and design: Ruparel, Patel, Kundnani. Acquisition of data: Patel, Dusad, Mehta, Kundnani. Analysis and interpretation of data: Patel, Kundnani. Drafting the article: Ruparel, Patel, Kundnani. Critically revising the article: Ruparel, Patel, Kundnani. Reviewed submitted version of manuscript: Ruparel, Patel, Kundnani. Approved the final version of the manuscript on behalf of all authors: Ruparel. Statistical analysis: Kundnani. Administrative/technical/material support: Kundnani. Study supervision: Ruparel, Kundnani.

\section{Correspondence}

Sameer Ruparel: Bombay Hospital, Mumbai, India. ruparelsameer@gmail.com. 